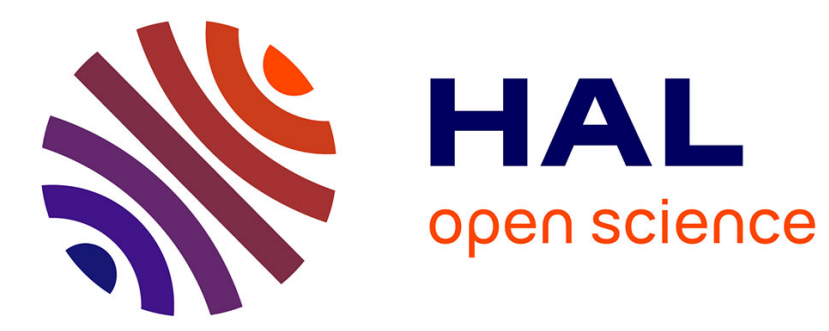

\title{
Influence of grain breakage on critical state
}

Wei Hu, Zhenyu Yin, Christophe Dano, Pierre-Yves Hicher

\section{To cite this version:}

Wei Hu, Zhenyu Yin, Christophe Dano, Pierre-Yves Hicher. Influence of grain breakage on critical state. IS-Model2012, 2012, Beijing, China. 10.1007/978-3-642-32814-5_20 . hal-01008325

\section{HAL Id: hal-01008325 \\ https://hal.science/hal-01008325}

Submitted on 22 May 2018

HAL is a multi-disciplinary open access archive for the deposit and dissemination of scientific research documents, whether they are published or not. The documents may come from teaching and research institutions in France or abroad, or from public or private research centers.
L'archive ouverte pluridisciplinaire HAL, est destinée au dépôt et à la diffusion de documents scientifiques de niveau recherche, publiés ou non, émanant des établissements d'enseignement et de recherche français ou étrangers, des laboratoires publics ou privés. 


\title{
Influence of Grain Breakage on Critical State
}

\author{
Wei Hu ${ }^{2, *}$, Zhen-Yu Yin ${ }^{3}$, Christophe Dano ${ }^{1}$, and Pierre-Yves Hicher ${ }^{1}$ \\ ${ }^{1}$ Research Institute in Civil and Mechanical Engineering, Ecole Centrale de Nantes \\ ${ }^{2}$ State Key Laboratory of Geohazard Prevention and Geoenvironment Protection, \\ Chengdu University of Technology, Chengdu, 610059, PR China \\ huwei1999@gmail.com \\ ${ }^{3}$ Department of Civil Engineering, Shanghai Jiao Tong University, Shanghai PR China
}

\begin{abstract}
Summary. This paper aims to investigate the influence of grain breakage on the position of the critical state line (CSL). Existing measures of the amount of grain breakage are discussed and a new measure named "relative uniformity" based on the evolution of the uniformity coefficient is proposed. Triaxial tests with different stress paths on granular materials made of limestone grains are carried out. Based on the obtained results, a method for determining the modified relative breakage index and the relative uniformity is proposed using plastic work. A relation between grain breakage measures and the position of the critical state line is then proposed for describing the influence of grain breakage on mechanical properties.
\end{abstract}

Keywords: Critical state, grain breakage, limestone grains.

\section{Introduction}

Grain breakage influences significantly the mechanical behaviour of crushable granular materials. The CSL changing with the grain size distribution (GSD) has been justified by experiments on sand (e.g. Bandini and Coop[1]; Biarez and Hicher[2]) and by numerical simulations using the discrete element method (e.g., Bolton et al. [3]; Kikumoto et al. [7]). The goal of this work is to propose a relation between the evolution of the CSL location and the measure of the amount of grain breakage during loading.

\section{Definition of Breakage Indexes}

Various grain breakage indexes have been proposed in the literature. Here, we retain the modified relative breakage index $B_{r}{ }^{*}=B_{t} / B_{p}$ proposed by Einav[6]obtained by replacing, in the definition by Hardin of the indexes $B_{p}$ and $B_{t}$, the cut-off line of silt particle size by an ultimate GSD. Since the GSD tends to be fractal according to McDowell and Bolton [8] and Coop et al. [4], the breakage measure $B_{r}{ }^{*}$

* Corresponding author. 
varies from zero to one with changes in GSD. This particular aspect might be convenient in practice. We also propose another coefficient called the relative uniformity $B_{u}$ based on the uniformity coefficient $C_{u}=D_{60} / D_{10}$ which varies with grain breakage, as follows

$$
B_{u}=\frac{C_{u}-C_{u i}}{C_{u f}-C_{u i}}
$$

another coefficient called the relative uniformity $B_{u}$ based on the uniformity coefficient where $C_{u i}$ represents the initial uniformity coefficient; $C_{u f}$ represents the ultimate uniformity coefficient corresponding to the fractal GSD. Thus, Bu varies also from zero to one.

\section{Relation between the Plastic Work and Breakage Index}

A possible variable related to the breakage amount can be the plastic work as proposed by Daouadji et al. [4] . We define the plastic work as follows:

$$
w_{p}=\int\left\langle\frac{1}{3} I_{1} \mathrm{~d} I_{1}^{\prime p}+2 \sqrt{J_{2} \mathrm{~d} J_{2}^{\prime p}}\right\rangle
$$

where $I_{1}$ and $\mathrm{d} I_{1}^{\prime p}$ are the first invariants of the stress tensor and of the incremental plastic strain tensor, respectively; $J_{2}$ and $\mathrm{d}_{2}^{\prime p}$ are the second invariants of the deviatoric stress tensor and of the incremental plastic deviatoric strain tensor, respectively; the function of MacCauley implies $\langle F\rangle=(|F|+F) / 2$. If Eq.(2) is adopted, the plastic work can be accumulated during cyclic loading. Monotonic and cyclic triaxial tests were performed on assemblies of limestone grains from a quarry located in Prefontaines, in the centre of France. This material is very crushable. The unit weight of the material is $17.1 \mathrm{kN} / \mathrm{m}^{3}$ and the specific weight is $27.0 \mathrm{kN} / \mathrm{m}^{3}$. The prepared samples have an initial uniformity coefficient $C_{u}=1.8$. The mean grain size is $D_{50}=6 \mathrm{~mm}$. The maximum and minimum void ratios are 1.43 and 0.83 , respectively. The initial void ratio $e_{0}$ for all tested samples varies from 1.05 to 1.1. Based on the stress-strain curves of all the above mentioned tests, the plastic work is obtained by using Eqs.(2). Then, $\mathrm{Bu}$ and $B_{r}{ }^{*}$ are plotted versus the plastic work, as shown in Fig. 1. For both monotonic and cyclic loading tests, the evolution of GSD can be expressed by a unique function of the plastic work, independent of the loading condition

$$
B_{u}=\frac{w_{p}}{a+w_{p}} ; \quad B_{r}^{*}=\frac{w_{p}}{b+w_{p}}
$$

with $\mathrm{a}=6500$ and $\mathrm{b}=1000$ for Préfontaines gravel. 

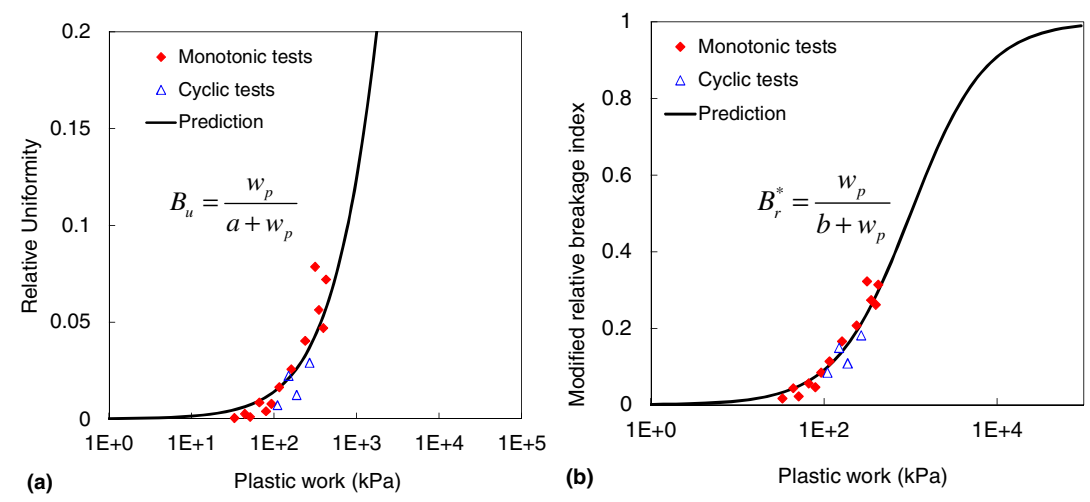

Fig. 1. (a) Relation between the plastic work and relative uniformity. (b) Relation between the plastic work and modified relative breakage index.

\section{Relation between the Plastic Work and Critical State Position}

For the tested material, in order to investigate the evolution of the CSL when grain breakage occurs, drained triaxial tests at a confining stress of $100 \mathrm{kPa}$ but with different stress histories were carried out. Based on the $e$-logp' curves of the different tests in Fig.2 with different amount of grain breakage, the hypothesis of a shift of the CSL can be justified. The equation of the CSL can be written as:

$$
e_{c}=e_{r e f}-\lambda_{c} \ln \left(\frac{p^{\prime}}{p_{a t}}\right)
$$

where ec is the critical void ratio corresponding to the current $p$ '; eref is the reference critical void ratio for a reference stress (taken equal to pat for convenience); $c$ is the slope of the critical state line in the $e$ - $\ln p$ ' plan. For the limestone material, the initial position of the CSL is given by $e_{r e f 0}=1.43$ and $c=0.153$, adopting the correlation of Biarez and Hicher. If the reference critical void ratio for each test is plotted as a function of the breakage measures $B_{u}$ and $B_{r}{ }^{*}$ (see Fig. 3), the evolution of the CSL location can be linked to the evolution of GSD, as follows:

$$
e_{r e f}=e_{r e f 0}-\Delta e_{r e f} \frac{B_{u}}{c+B_{u}} ; e_{r e f}=e_{r e f 0}-\Delta e_{r e f} \frac{B_{r}^{*}}{d+B_{r}^{*}}
$$

with $e_{\text {refo }}=1.43, e_{\text {ref }}=0.5, c=0.006$ and $d=0.035$ obtained by curve fitting. Substituting Eq.(3) into Eq.(5), the reference critical void ratio can also be directly related to the plastic work, as follows:

$$
e_{r e f}=e_{r e f 0}-\Delta e_{r e f} \frac{w_{p}}{a c+(1+c) w_{p}}
$$



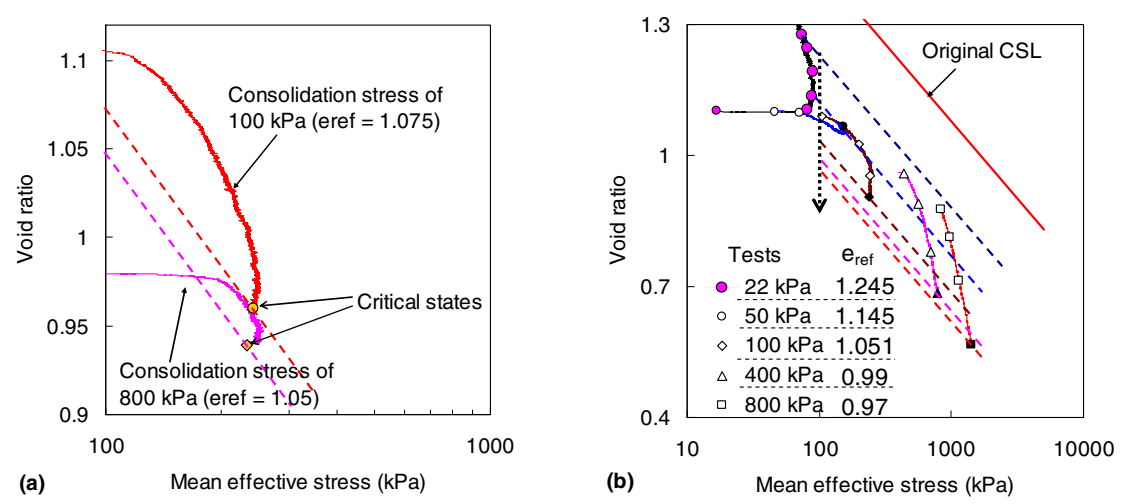

Fig. 2. Movement of CSL in e-logp' plane for: (a) tests with different consolidation stress histories, (b) tests with different confining stresses
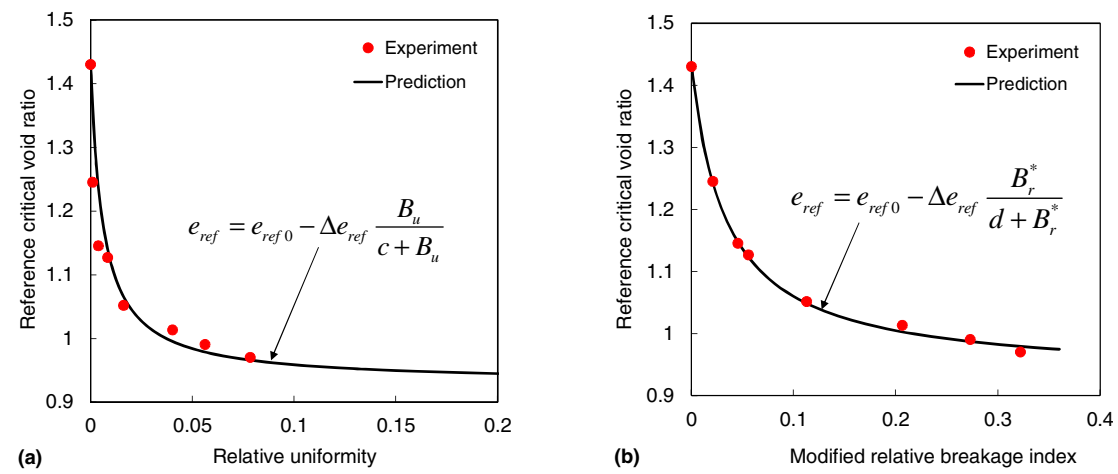

Fig. 3. (a) Reference critical void ratio versus relative uniformity, (b) Reference critical void ratio versus modified relative breakage index

\section{Conclusions}

Triaxial tests with different stress paths under both monotonic and cyclic loadings on limestone grain assemblies were carried out. Based on experimental observations, the evolution of the breakage measures $B_{u}$ and $B_{r}{ }^{*}$ representing the evolution of GSD due to grain breakage under both monotonic and cyclic loading conditions are shown to be both an hyperbolic function of the plastic work, independently of the nature of the loading. Furthermore, the shift of the critical state line due to grain breakage was also investigated. Based on the results obtained on the limestone grain material, a relation between the breakage measures and the CSL location is proposed. Therefore, the shift of the CSL can be determined at any stage of a given test by calculating the plastic work accumulated from the beginning of the mechanical loading. 


\section{References}

[1] Bandini, V., Coop, W.R.: The influence of particle breakage on the location of the critical state line of sands. Soils and Foundations 51(4), 591-600 (2011)

[2] Biarez, J., Hicher, P.Y.: Elementary Mechanics of soil behaviors. Balkma, Rotterdam (1997)

[3] Bolton, M.D., Nakata, Y., Cheng, Y.P.: Micro- and macro-mechanical behaviour of DEM crushable materials. Géotechnique 58(6), 471-480 (2008)

[4] Coop, M.R., Sorensen, K.K., Bodas Freitas, T., Georgoutsos, G.: Particle breakage during shearing of a carbonate sand. Géotechnique 54(3), 157-163 (2004)

[5] Daouadji, A., Hicher, P.Y., Rahma, A.: An elastoplastic model for granular materials taking into account grain breakage. European Journal of Mechanics - A/Solids 20(1), 113-137 (2001)

[6] Einav, I.: Breakage mechanics- Part I: Theory. Journal of the Mechanics and Physics of Solids 55(6), 1274-1297 (2007)

[7] Kikumoto, M., Muir Wood, D., Russell, A.R.: Particle crushing and deformation behaviour. Soils and Foundations 50(4), 547-563 (2010)

[8] McDowell, G.R., Bolton, M.D.: On the micromechanics of crushable aggregates. Géotechnique 48(5), 667-679 (1998) 